\title{
Target-Driven Sustainable Product Development
}

\author{
Tom Buchert, Anne Pförtner and Rainer Stark
}

\begin{abstract}
Figuring in sustainability in product development requires a profound understanding of the cause and effect of engineering decisions along the full spectrum of the product lifecycle and the triple bottomline of sustainability. Sustainability design targets can contribute to mitigating the complexity involved, by means of a formalised problem description. This article discusses how sustainability design targets can be defined and presents methods for systematically implementing these targets into the design process. To that end, different means of decision support mechanisms are presented. They comprise (a) use cases of target breakdowns in subsystems, (b) systematic reduction of solution space and (c) assistance in design activities to ensure achievement of sustainability design targets. This paper explains how interfaces to engineering tools such as Computer Aided Design/Engineering (CAD/CAE) or Product Data/Lifecycle Management (PDM/PLM) can be put in place to make the process of retrieving information and providing decision support more seamless.
\end{abstract}

Keywords Decision support - Sustainable design - Product development • Sustainability targets

\section{Challenges in Sustainable Product Development}

The topic of Sustainable Product Development (SPD) has been discussed in academic research since the early nineties with a strong focus on the environmental perspective (e.g. by Allenby 1991). In this context, numerous approaches have been developed, while some success-stories, e.g. the diffusion of LCA into industrial

T. Buchert $(\bowtie) \cdot$ A. Pförtner

Technische Universität Berlin, Berlin, Germany

e-mail: Tom.buchert@tu-berlin.de

R. Stark

Chair of Industrial Information Technology, Institute for Machine-tools and Factory

Management, Technische Universität Berlin, Berlin, Germany

(C) The Author(s) 2017

R. Stark et al. (eds.), Sustainable Manufacturing, Sustainable Production,

Life Cycle Engineering and Management, DOI 10.1007/978-3-319-48514-0_9 
practice (Kara et al. 2014), have been achieved. However, nearly thirty years after the sustainability debate emerged, industrial production remains far from being sustainable [e.g. in the sense of exceeding planetary boundaries (Steffen et al. 2015)]. This insight leads to the question of what specific challenges need to be overcome in product design to improve the overall situation.

From a practical perspective, a range of factors influence the successful implementation process of SPD, such as:

- personal motivation of actors (e.g. incentives for fostering sustainability integration into product design),

- available resources (e.g. time budget for SPD method application) or

- lock-in effects (e.g. existing contracts with suppliers of unsustainable materials).

While these practical barriers can be solved by appropriate managerial oversight in the respective companies, great potential remains untapped in the research on SPD. A major challenge in this context is to find solutions for decreasing the complexity attached to SPD decision-making. Yet a sustainable design can only be achieved if design engineers develop subsystems in accordance with their influence on the triple bottomline (economic, environmental and social sustainability) at each and every step along the way of the entire product lifecycle (see Fig. 1). One approach for coping with this complexity is to break the problem down to smaller sub-problems which are easier to handle (problem modules). Figure 1 gives an example of which modules can be considered in the context of SPD (e.g. environmental impacts of electronic recycling).

Nevertheless, this reductionist approach may not prove to be sufficient due to the diverse interrelations between problem modules (e.g. better recyclable electronics may lead to economic problems in production). A key task of SPD research

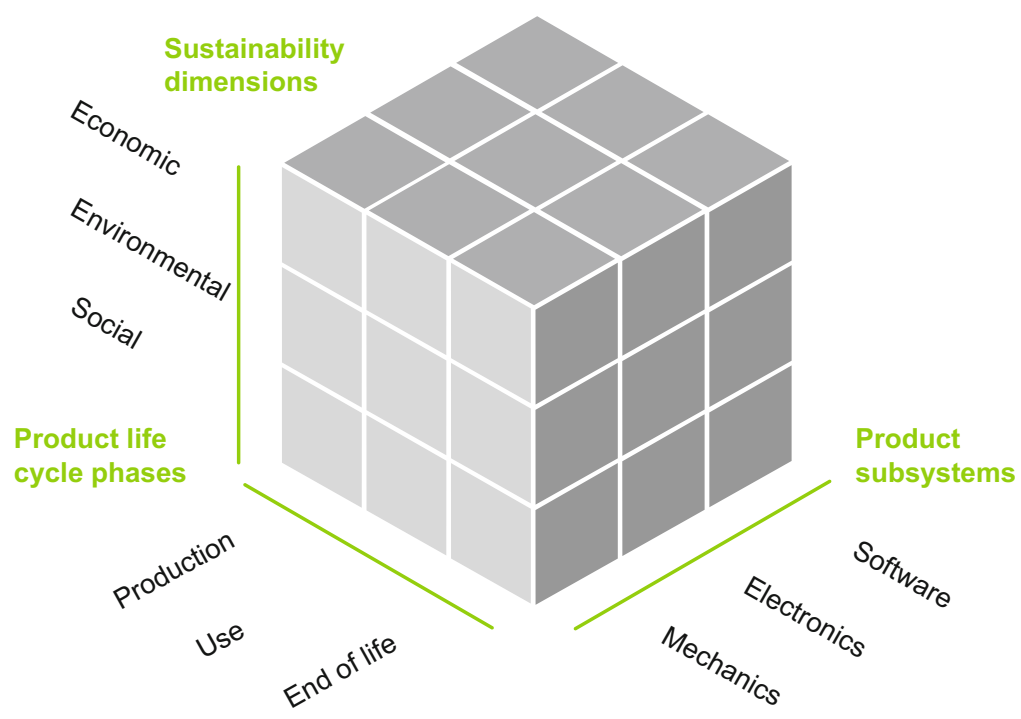

Fig. 1 Modules of sustainable product development problems 
therefore lies in enabling engineers to anticipate these dependencies by means of methodological guidance as well as by enhanced knowledge and information supply. Thus, rather than searching for solutions to specific problem modules, this article will focus on providing novels mechanisms for increasing the transparency of decision-making.

\section{Methods for Supporting Decision-Making in SPD}

A wide variety of approaches for supporting decision-making in SPD have been developed in the last years. Baumann et al. (2002) classify existing approaches for environmental sustainability into six categories which still apply today in the field of SPD:

Analytical tools try to quantify the impact on the three dimensions of sustainability with varying precision. Life Cycle Sustainability Assessment as a combination of Life Cycle Assessment, Life Cycle Costing and Social Life Cycle assessment (Neugebauer et al. 2015) is utilised for more accurate estimations in later design phases, at which point plenty of information about the product is available. More simplified approaches (e.g. by Collado-Ruiz and Ostad-Ahmad-Ghorabi 2013) can be utilised in earlier phases as a form of heuristic prediction of impacts.

Checklists and guidelines provide best practices for guiding engineers along in the design process. They can be utilised in the early phases but are less helpful for decision-making for specific design problems. In the environmental realm, exhaustive collections of design guidelines have long since existed (Telenko et al. 2016). Guidelines for sustainable design are scarce. The most mature approach is based on a modular set of guiding questions which are also referred to as "templates" (Ny et al. 2008).

Rating and ranking tools provide possibilities for the simple but structured comparison of different solution options, based mostly on qualitative or semiquantitative evaluation (see for example Shuaib et al. 2014).

Organizing tools furthermore help structure the design process by involving multiple stakeholders in the form of workshops or structured interviews.

Software and expert systems assist in applying methods by automating certain steps of the method application or by simplifying the process of researching for information through databases (e.g. LCA software such as GaBi. ${ }^{1}$ Furthermore, IT-support of this kind has the potential to enable one's own methodological approaches like the Eco-Pas software tool by Duflou and Dewulf (2005). The latest approach for IT-based decision support is the integration of SPD methods in engineering tools like CAD (e.g. Solidworks Sustainability Pro $^{2}$ and in PDM systems (Ciroth et al. 2013). Nevertheless, these approaches are limited to the

\footnotetext{
${ }^{1}$ https://www.thinkstep.com/software/gabi-lca/.

${ }^{2}$ http://www.solidworks.de/sustainability/.
} 
assessment of the current design progress and the relative comparison to a reference design without actual guidance. Furthermore, the underlying impact model and the dependencies between engineering decisions as well as the sustainability impact have all yet to be made transparent to the engineer. In particular, trade-offs between the sustainability dimensions are not being intensively researched since most of available methods focus on the environmental sustainability perspective. The following three characteristics summarise insights on methods for sustainable product development (see Buchert et al. 2014 and Sect. 4.3):

- Existing methods focus on assessment. There is a lack of engineering approaches that assist engineers in the form of offering support for design synthesis. Guidelines can be utilised for synthesis but are often not sufficient for addressing a specific design problem.

- Availability of information in conceptual design is usually scarce. Analytic approaches require a lot of information and are therefore only utilised once major decisions have already been made.

- Insufficient transparency on system relations between product design decisions, sustainability impacts and product life cycle stages prohibits a systematic examination of the specific trade-offs and side-effects attached to engineering decisions.

\section{Integration of Sustainability Targets into the Design Process}

The complexity of cause and effect chains presents a major challenge for judgment calls in sustainable product development. One favourable way of reducing the complexity factor in the whole process lies in defining targets which specify the most relevant influencing factors for the problem and which provide a basis from which to develop further decision-making models (Bretzke 1980). Hence, it needs to be clarified how "sustainability design targets" can be formulated in a complimentary fashion to basic technical or functional requirements. A starting point for addressing this problem is to pinpoint the causal relations between engineering decisions and sustainability impact. This is achieved by classifying different types of information to different categories in a fixed order illustrated in Fig. 2. The categories and their respective relationships will be introduced in the following paragraphs. A more detailed description can be found in (Buchert et al. 2016).

The scheme developed is based on the separation of product characteristics (I) and properties (II) as defined by Weber et al. (2003) in the scope of their "Property Driven Product Development (PDD)" approach. Category (III) refers to the sustainability impact of a product on various stakeholders such as the environment, health aspects of employees and customers as well as the financial stability of the company (III). In order to connect the design engineering perspective (I and II) with the sustainability impact view (III), the category product properties 


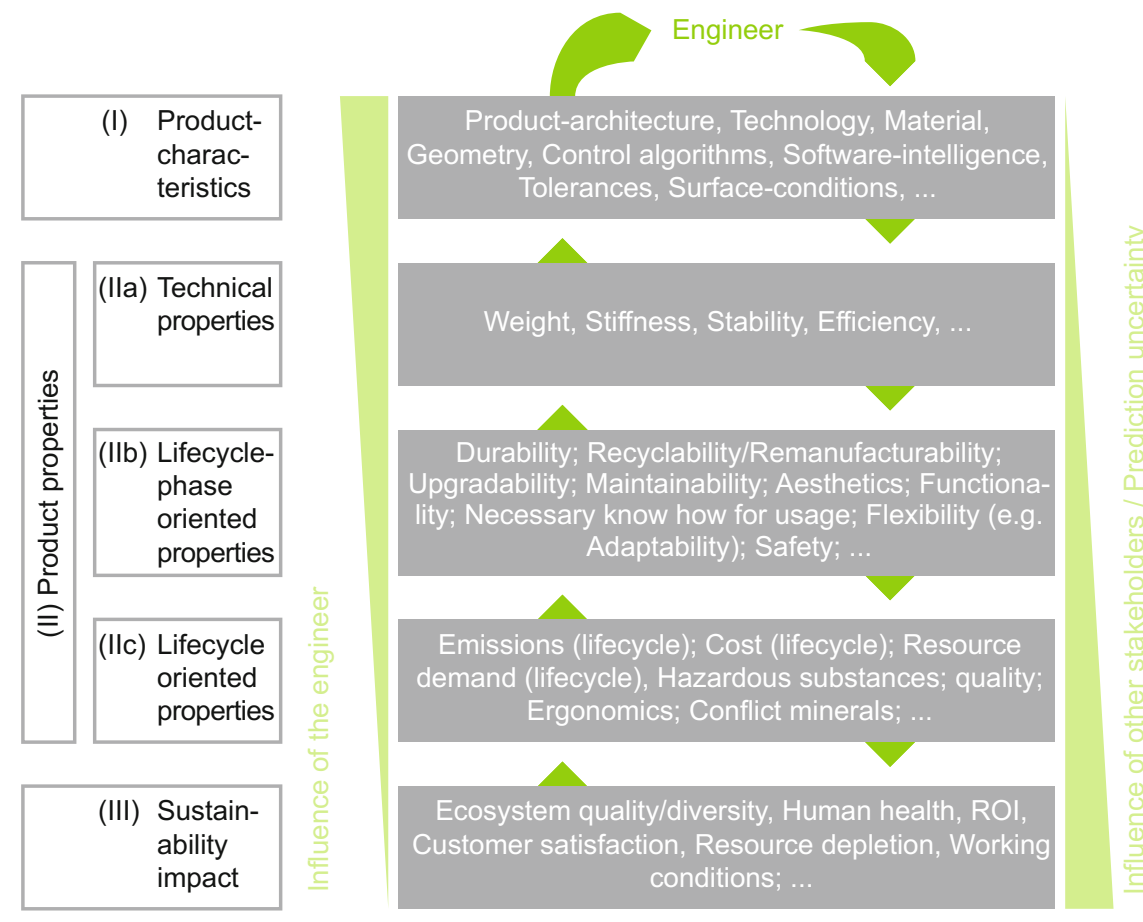

Fig. 2 Scheme for linking design decisions to sustainability impact (Buchert et al. 2016)

was subdivided into three subclasses, each of which takes the perspective of the product life cycle (IIa-IIc) into consideration. Category IIa consists of technical properties that are defined directly as a result of engineering decisions for product characteristics. The definition of the characteristic's material and geometry defines, for example, the technical property weight. When technical properties are combined and enriched with influences from outside the system, boundary lifecycle-phase oriented properties are determined (IIb). The prediction of durability in the usage phase of a pedelec frame is, for example, based on technical properties such as tensile strength or stiffness, but also relies on user behaviour. This type of property defines how a product interacts with its surrounding systems within specific lifecycle phases (e.g. durability, remanufacturability). If all effects of these interactions are aggregated along the product lifecycle, (e.g. in terms of cost or emissions) lifecycle-oriented properties are then derived (IIc). Lifecycle oriented properties can be understood analogous to the term Lifecycle Inventory which is used in the context of Life Cycle Assessment to evaluate environmental sustainability.

By analysing the complete scheme, it becomes evident that the influence of engineering decisions decreases with every level, since other actors in product creation (e.g. sourcing) likewise have a significant influence on overall product sustainability impact. Furthermore, external influences (e.g. user behaviour) may deviate from assumptions stemming from the design process and therefore increase 
uncertainty of predictions for the whole lifecycle of a product. One conclusion from this analysis is that targets on impact level are less appropriate for design engineers since they are not trained to relate their actions properly to impact indicators. Hence, sustainability experts need to be involved in the design process, which serves to make the most critical lifecycle-oriented properties and the most significant lifecycle phases for engineering target definition identifiable. In addition to sustainability experts, other company roles may also define relevant targets in a sustainability context, in particular from an economic perspective (e.g. product or quality managers).

Figure 3 provides a reference framework for integrating sustainability targets into the design process by differentiating between different stakeholders involved and by identifying challenges for successful target integration. Potential for decision support in the other direction is identified with this framework. Respective challenges are introduced in the following paragraphs.

Once sustainability targets are defined by the respective experts, they then have to be broken down into technical subsystems or assemblies by system engineers (see Fig. 3). This step poses a special challenge, since it is not clear how narrowly a target should be formulated in order to be effective in the sense of sustainability improvement. It can be argued which level of the scheme shown in Fig. 2 is most appropriate for which respective purpose. The more specifically the target is defined (e.g. on the level of technical properties such as weight), the less opportunities remain for domain engineers to find a creative solution to foster sustainability performance. Furthermore, unintended side effects can occur since the domain

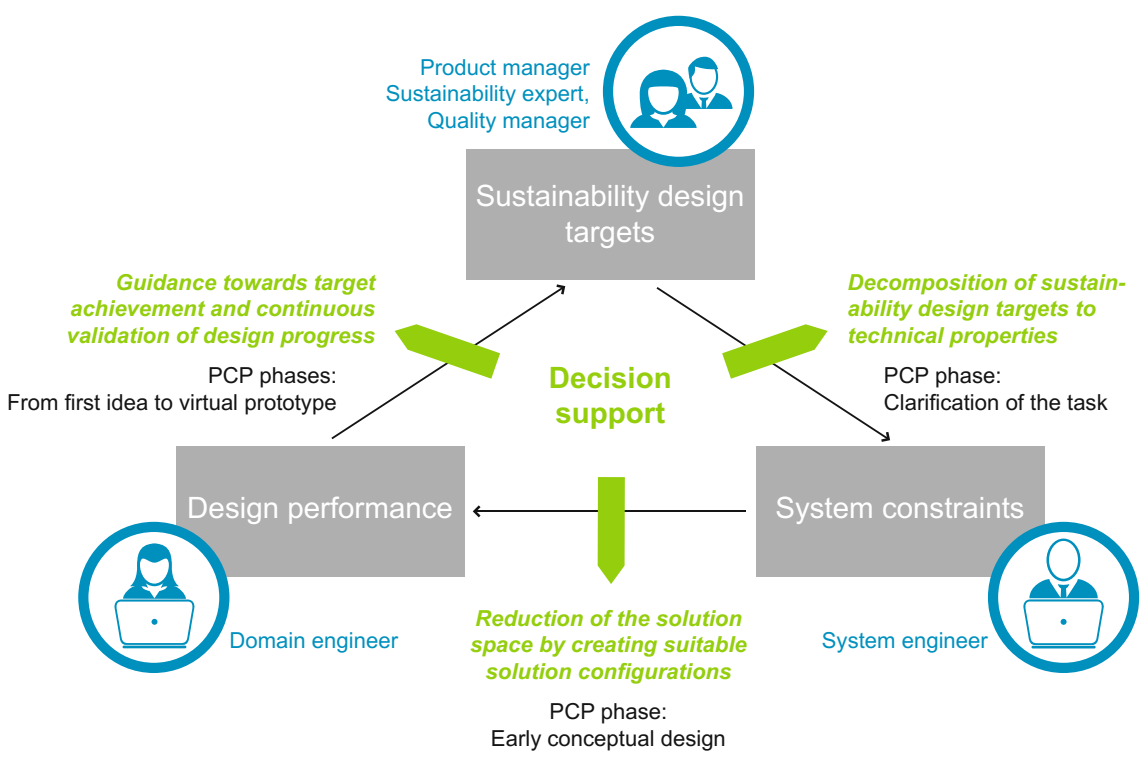

Fig. 3 Framework for decision support based on sustainability design targets 
engineers may not be informed about the intended effect of the target in terms of sustainability improvement (e.g. changing to a lighter material to save fuel consumption of a car may shift the environmental burden to material production). In this context, how exactly targets should be allocated to subsystems for establishing the basis for a sustainable solution configuration also needs to be evaluated.

Another challenge which needs to be overcome to properly address sustainability targets in the design process, lies in the identification of sustainable and technically feasible configurations of system elements and inherent product characteristics. This task is troublesome since multiple configurations are possible, and it also needs to be determined which components can be reused and where new developments are necessary. This reduction of the solution space decreases the effort for further design activities and therefore increases efficiency and effectiveness of the design process.

Domain engineers then finally develop suitable solutions according to the given requirements. In that pursuit, it is necessary to evaluate whether the current design process and estimated product performance in different PCP stages are compliant with given sustainability design targets. Furthermore, providing specific advisory tips towards achieving these targets can be beneficial. Hence, a range of activities might be necessary, such as, ideation for new and more sustainable products, comparison of solution concepts, and/or final solution assessment. A broad set of methods has been developed for assisting in these tasks. The challenge therein lies in selecting the right method for each and every task along the way in the product development process.

The challenges described are also summarised in Fig. 3 and are viewed by the authors a handy framework of reference for implementing sustainability targets in the design process. Decision support tools can play a viable role in overcoming these challenges by fostering transparency on sustainability cause and effects and by increasing the availability of information for the engineer. New approaches for decision support to that effect are therefore presented in the following chapters addressing these aspects.

\section{Decision Support for Integrating Sustainability Design Targets}

This section introduces three concepts for addressing the challenges for integrating sustainability targets into the design process. The respective approaches are explained based on the example of a pedelec (i.e. an electric bicycle) redesign project. Exemplary questions raised within the scope of this project are illustrated in Fig. 4 and will provide use cases for decision support mechanisms which have been developed. 


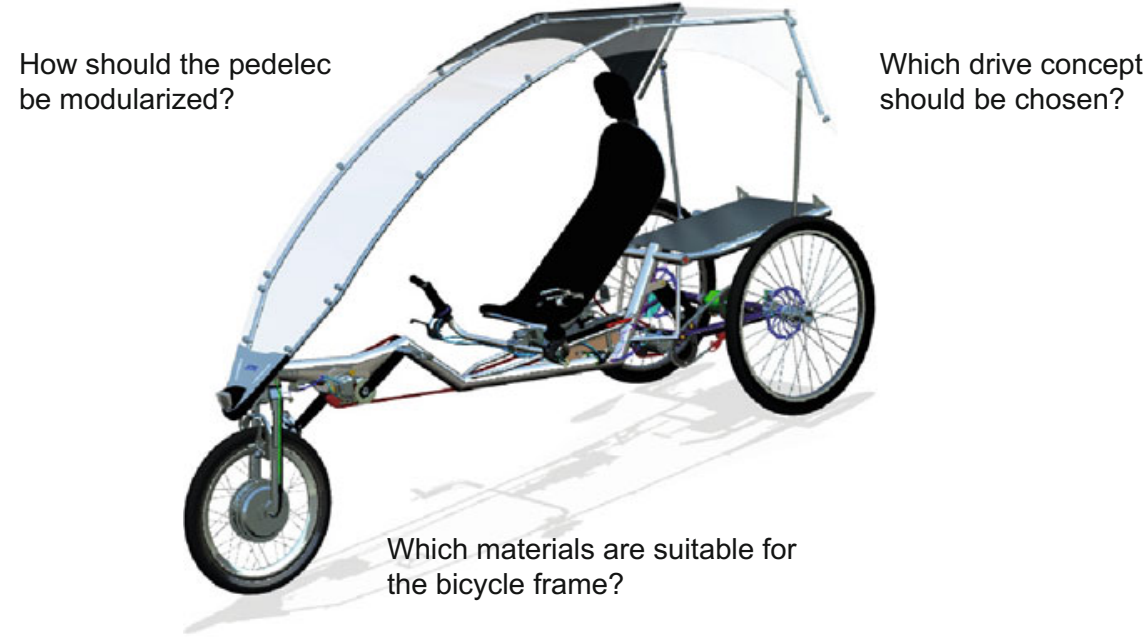

Fig. 4 Exemplary engineering decisions with an influence on pedelec sustainability

\subsection{Breakdown of Sustainability Targets for Product Architecture Decisions}

Proper breakdown of sustainability targets from desired impacts to technical influencing-factors introduces an array of hurdles for design teams. Yet defining targets at the system level and for respective subsystems can be seen as one of the most crucial tasks in the design process, since the basis for implementing engineering strategies is defined in this step. In many companies, heuristics are followed to define their strategies. Automotive companies choose, for example, "lightweight design" to reduce fuel consumption of their vehicles. The problem with heuristics is that they are often formulated for one specific target without considering side-effects and concomitant relations with other company targets. Thus, it can be helpful to give an overview of which options are available to achieve targets or, on the flip-side, to see which indicators can be affected by design changes. A good example of a missing link in cause and effect chains can be found when considering decision-making on product architecture. The majority of companies modularise their products to limit internal complexity, to decrease their time to market, and to increase external variance for customers at the same time (Gleisberg et al. 2012). Nevertheless, other relevant targets have to be considered, such as flexibility of the product to allow multiple product use-cases and disassembly to provide reuse opportunities or simplification of maintainability.

In order to increase the transparency of relations between modularisation decisions and sustainability targets, a qualitative concept map was developed. An extract of the map is displayed in Fig. 5. The full map contains 77 modularisation drivers (i.e. targets and sub-targets) and 44 modularisation metrics. The map is 
structured from top to bottom regarding the information categories identified in Fig. 2 and the type of decisions addressed (from strategic to tactic and from tactic to operational level). The grey boxes visualised in Fig. 5 mark one possible way through the map starting with sustainability targets on impact level at the top. This particular way is explained for the example of setting targets for a pedelec architecture definition. At impact level (III), different sustainability indicators may be relevant for a pedelec. In this example, climate change and customer value were chosen as important impact categories. In practice, the selection of indicators relies on legal requirements as well as on company strategy, which may also include

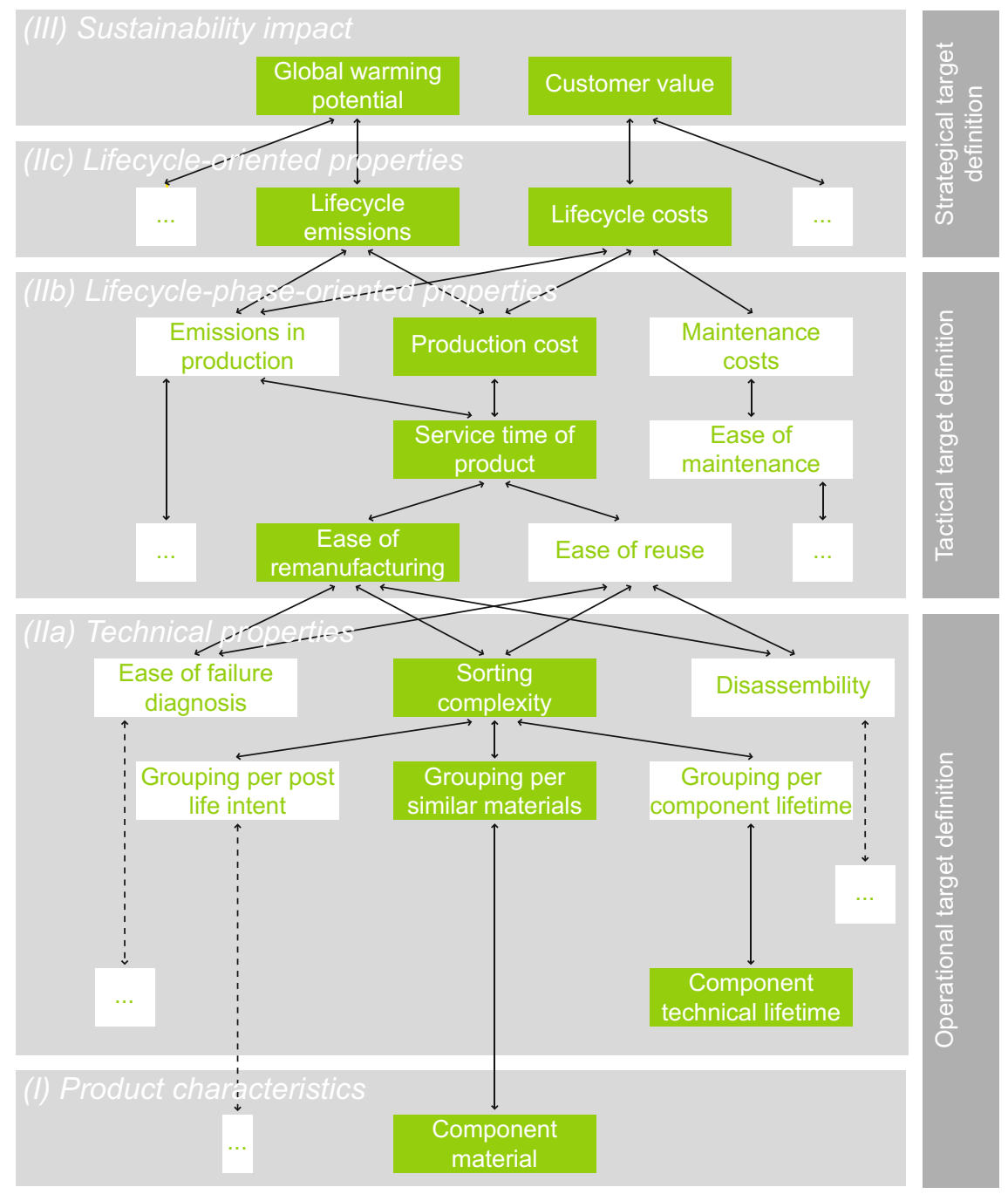

Fig. 5 Concept map for illustrating targets for product architecture definition 
voluntary agreements. Customer value relies on the total cost of ownership (lifecycle cost) of the pedelec. Yet, there are also other factors to consider, such as functionality, which can be enhanced by upgradeability of the pedelec (e.g. with a stronger motor or an additional roof). The environmental impact category Climate Change is determined by total greenhouse gas emissions (GHG) along the pedelec lifecycle.

To reduce total emissions, the production phase of the pedelec should be considered since it contributes almost half of the total GHG emissions of a pedelec (Neugebauer et al. 2013). The most important contribution of modularisation at decreasing GHG emissions in production is to increase the time the product can be used (service time), since a longer utilisation period ultimately decreases the amount of products which have to be manufactured. If less products need manufacturing, absolute production cost likewise decreases. Furthermore, remanufacturing or reusing are possible measures for increasing the service time of the product. Both End of Life (EOL) options can be fostered by increasing the ease of disassembly or by grouping components in such a way that the sorting of components can be improved upon (e.g. by clustering components with same materials).

In contrast to other product characteristics, like material or geometry decisions, sustainability targets cannot be broken down to the individual component level (e.g. a targeted efficiency of a motor). Targets for modularisation can only be formulated on a system level since modularisation considers how different components are organised.

By going through the map, it should be noted that the strategic paths chosen may also lead to side effects. Increasing service time may, for example, impact the business model by decreasing sales revenue due to the fact that less products are sold. Furthermore, production could turn out to be less efficient, leading to the necessity of downsizing the production system. Smaller production may lead to personnel shifts, layoffs etc. Due to this multitude of effects, it can be difficult to find a suitable system boundary for strategic modularisation decision-making. Furthermore, missing quantification of relations between targets and modularisation metrics poses a barrier toward the quantitative assessment of modularisation effects. For enhanced decision-making in support roles, new quantified models for modularisation impact will thus have to figure into play (see Sect. 5).

\subsection{Model Based Reduction of the Solution Space}

Targets which are broken down and formulated as constraints can be used to reduce the solution space and eliminate the design solutions that do not comply with the defined constraints. Calculating the fulfilment of constraints for possible solutions manually is however time-consuming. Each option for all variable characteristics (e.g. each material and geometric parameters) would have to be assessed in order to determine all the viable solutions. If relations between a choice of characteristic and constraints associated with a target are formalised on a quantitative basis, viable 
solutions can be calculated automatically. Consequently, a formalised model expands the option pool for considering a high amount of configurations and multiple targets. Configuration options from predecessor products can be used as a basis for identifying solution options (Buchert et al. 2016). This model-based approach shall now be demonstrated with the simple example of a pedelec frame.

Based on a previous LCA study, emissions for wrought material production were identified as an important lifecycle phase oriented property (Neugebauer et al. 2013). Hence, the indicator " $\mathrm{CO}_{2}$ emissions in material production" was selected as a sustainability target for improving the pedelec frame. Furthermore, the durability of the pedelec frame in the use phase was chosen as a second target. The frame-durability determines a part of the value provided to the customer and may contribute to an overall reduction of $\mathrm{CO}_{2}$ emissions if the lifetime of the pedelec is extended. Another reason for choosing durability as a target is to verify that a decision on material matters does not negatively affect the use-phase of the bicycle frame. Durability is a lifecycle-oriented property implying that influences (load and forces) from the respective lifecycle phase (use phase) are either assumed based on experience or on user studies or empirical studies of similar processes. The accurate determination of the frame durability would require a combination of different models for simulating the material strength under both static and dynamic load as well as for usage behaviour. In that pursuit, durability was examined by means of simplified analysis of axial frame deformation and v. Mises strength in comparison to tensile strength of the material. Figure 6 displays the causal relations between durability and $\mathrm{CO}_{2}$ emission in material extraction with the product characteristics material and geometry.

Durability is dependent on the stiffness of the frame and on forces applied during use. The relations between material parameters such as young's modulus and stiffness follow principles of physics. The causal relations can thus be captured in



Fig. 6 Relations to calculate lifecycle oriented properties 
mathematical equations. The v. Mises strength and the deformation can be calculated by an automatic FEM analysis. An existing frame CAD and FEM model from a predecessor product were utilised as a basis for the respective calculations. Since the new design may deviate from the original frame, the results calculated can only be understood as heuristic. Nevertheless, the process yields valuable insights about which materials are suitable for given requirements already in conceptual design, with the assumption that the frame design does not change significantly.

Figure 7 gives an example of how the data model for a decision support tool can be structured. The classes are instantiated for the selection of a material for the pedelec frame. The following dependencies between different classes of information were formalised:

- Constraints (broken down targets) are associated with product properties.

- Product properties can be calculated based on further properties, constants or characteristics.

- The $\mathrm{CO}_{2}$ emission for wrought material, for example, can be calculated by the property mass times the constant $\mathrm{CO}_{2}$ emissions per $\mathrm{kg}$ wrought material.

- The constant $\mathrm{CO}_{2}$ emissions per $\mathrm{kg}$ can be derived from an environmental database, e.g. the ELCD database, thus through an IT-interface.

- IT-interfaces require certain data, in this case the ELCD material name, in order to yield the desired information $\mathrm{CO}_{2}$ emissions per $\mathrm{kg}$ material.

- Mass is calculated by volume and density for the material.

- The volume can be easily calculated by a CAD system.

- Possible values for the characteristic (e.g. specific materials) are automatically derived from a repository which is linked to the model. In the case of the pedelec, all materials from the Siemens NX database were taken into consideration.

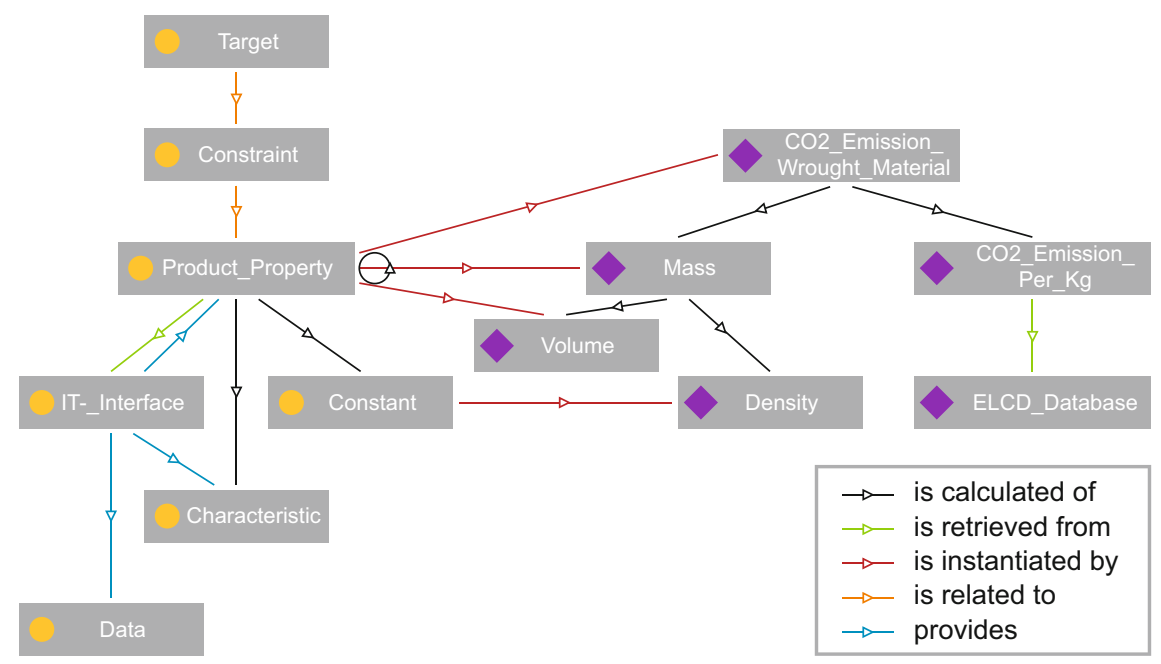

Fig. 7 Meta model for target calculation with exemplary instantiation 
The software tool interprets all the interconnected steps independently, starting from a target and proceeding up until the point when it reaches an IT-database. The tool then derives the required information and successively inserts the information derived or calculated until a value for the product property concerning a selected constraint can then be calculated. The benefit of this approach is that all (discrete) values for a characteristic can be automatically iteratively assessed even if the required information is dispersed among different IT-tools. The IT-tools are accessed by respective interfaces e.g. a Service Oriented Architecture (SOA) interface. If all relevant relations are modelled according to the meta-model, the software tool can automatically calculate viable values for a characteristic and thus exclude unfitting solution options and reduce the solution space.

In the case of the pedelec frame, the tool proposed 5 different steel versions which fulfill the $\mathrm{CO}_{2}$ emission and the deformation and strength constraints as a proof of concept. However, not all materials were listed in the ELCD database and were therefore excluded. Otherwise more suitable options could have been derived. The mapping of different material databases moreover remains imprecise and requires further research in order to boost accuracy. A more detailed description of this first model prototype can be found in the publication of Stark and Pförtner (2015).

A discussion of how the use case can be extended to assemblies and entire product systems can be found in Sect. 5 .

\subsection{Guidance for Achieving and Proving Compliance with Sustainability Targets}

When sustainability design targets are formulated, engineers have to take action to prove that compliance with these targets in all stages of the PCP. Furthermore, guidance is necessary for assisting engineers in achieving the respective targets. These activities can be steered and supported by design methods. Since many methods for Sustainable Product Development (at least concerning environmental sustainability) are available, Ernzer and Birkhofer stated already in (2002) that: "the difficulty [...] is not the development of design methods anymore, but rather the ability to select the relevant methods." Hence, a scheme for selecting and combining methods was developed, which allocates a suitable approach to designing activities necessary for achieving or proving adherence with a sustainability target. The approach consists of a taxonomy of SPD methods and a method repository including 29 design methods. Figure 8 shows the three major steps for method selection and application. Step 1 characterises the definition of milestones. Milestones constitute a point of time in a design project where the achievement of a sustainability design target has to be proven.

A relevant sustainability target for a pedelec redesign process could be, for example, to decrease cost and $\mathrm{CO}_{2}$ emissions in the usage phase with reference to what specific elements could be broken down into various alternatives for a drive 
Step I Definition of design process and milestone targets

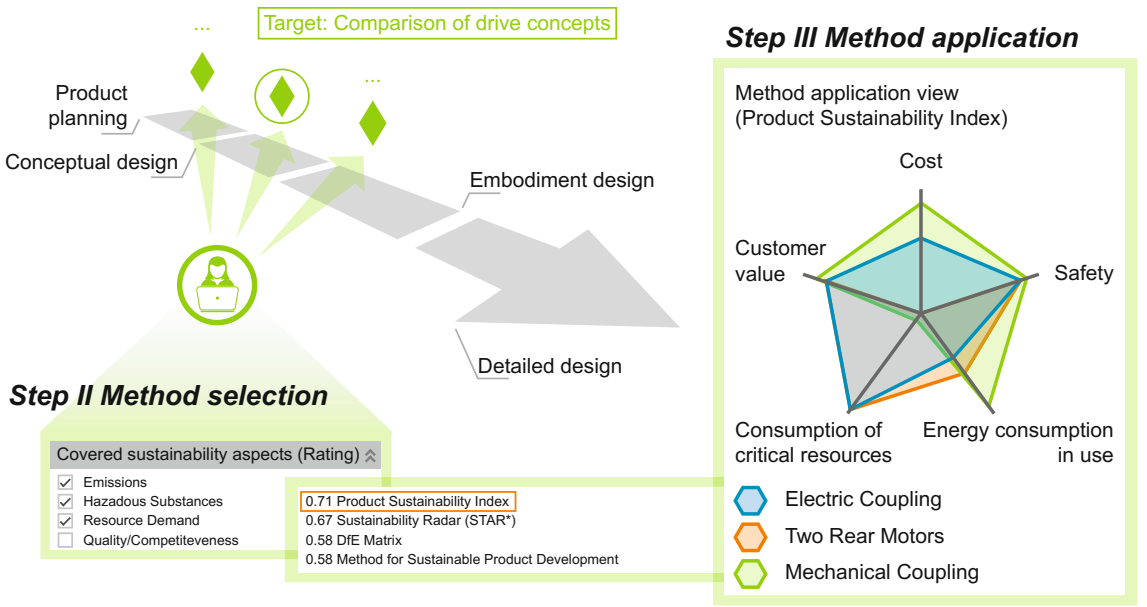

Fig. 8 Method selection and application feature for guiding engineers and to validate design performance against sustainability design targets

concept. Hence, a comparison of variants for the drive concepts regarding $\mathrm{CO}_{2}$ emission and cost is necessary for the process of reporting results at a milestone towards the end of the conceptual design phase.

The second step (see Fig. 8) aims at selecting a suitable method for achieving targets defined in step 1 . To that end, a taxonomy of design methods was put together (see Table 1).

The taxonomy outlines the design activity which the method supports (e.g. assessment), as well as information about the effort and information inputs required. Furthermore, it considers the type of targets which can be addressed by the method (e.g. addressed sustainability aspects or quantification of the target).

Complimentary to the taxonomy development, 29 SPD methods were successfully identified which were found to be compliant with predefined criteria (e.g. coverage of the whole product lifecycle, accessibility or a focus on technical products). Figure 9 shows an example for proving achievement of sustainability targets by selecting appropriate methods for the pedelec drive concept.

In addition to improved method selection, a concept for fostering application of methods was also implemented for three different methods (Pförtner et al. 2016). The main idea behind this approach was the development of an information platform which stores sustainability relevant information for a product and makes it available for the application of various methods. Only by following this approach does a combination of different SPD methods become attractive, since effort for information search can therein be reduced. Both the selection scheme and the information platform were implemented in the PDM system Siemens Teamcenter. Hence, necessary product-information (e.g. product structure, weight) can be imported. Further drawbacks and advantages of the approach are presented in Sect. 5. 
Table 1 Taxonomy criteria for method selection

\begin{tabular}{l|l}
\hline Criterion & Options \\
\hline Method purpose & $\begin{array}{l}\text { Identification of improvement measures, comparison, assessment, } \\
\text { direct selection of product characteristics based on targets }\end{array}$ \\
\hline Quantification & Qualitative, quantitative, semi-quantitative \\
\hline $\begin{array}{l}\text { Covered sustainability } \\
\text { targets }\end{array}$ & $\begin{array}{l}\text { Emissions, hazardous substances, resource demand, } \\
\text { quality/competitiveness, safety, material origin, cost }\end{array}$ \\
\hline User of the method & Product manager, product designer, sustainability expert \\
\hline Effort for application & $1=$ low, 2 middle, $3=$ high \\
\hline $\begin{array}{l}\text { Necessary information } \\
\text { for application }\end{array}$ & $\begin{array}{l}\text { Requirements/functions, solution concepts, product architecture, } \\
\text { CAD files/EBOM, production process/MBOM, auxiliary } \\
\text { information }\end{array}$ \\
\hline Redesign focus & Yes/no \\
\hline
\end{tabular}

\begin{tabular}{|c|c|c|c|}
\hline & Conceptual design & Embodiment design & Detailed design \\
\hline $\begin{array}{l}\text { Milestone for } \\
\text { validating } \\
\text { sustainability } \\
\text { targets }\end{array}$ & $\begin{array}{l}\text { M1: Validation of } \\
\text { emission and costs } \\
\text { targets }\end{array}$ & $\begin{array}{l}\text { M2: Validation of } \\
\text { legal compliance }\end{array}$ & $\begin{array}{l}\text { M3: Validate } \\
\text { emission and cost } \\
\text { targets }\end{array}$ \\
\hline $\begin{array}{l}\text { Design } \\
\text { activities for } \\
\text { achieving } \\
\text { sustainability } \\
\text { targets }\end{array}$ & $\begin{array}{l}\text { T1: Identify improve- } \\
\text { ment potential for } \\
\text { reduction of emission } \\
\text { and cost }\end{array}$ & $\begin{array}{l}\text { T2: Assessment of } \\
\text { RoHs compliance } \\
\text {-T3: Assessment of } \\
\text { conflict minerals } \\
\text { compliance }\end{array}$ & $\begin{array}{l}\text { T4: Validate emission } \\
\text { and cost targets }\end{array}$ \\
\hline Responsible & - Design engineer & $\begin{array}{l}\text { Design engineer; } \\
\text { Sustainability Expert }\end{array}$ & $\begin{array}{l}\text { Design engineer; } \\
\text { Sustainability Expert }\end{array}$ \\
\hline $\begin{array}{l}\text { Selected } \\
\text { design }\end{array}$ & Eco Value Analysis & $\begin{array}{l}\text { RoHs \& Conflict } \\
\text { minerals checklist }\end{array}$ & LCA \& LCC \\
\hline
\end{tabular}

Fig. 9 Exemplary method selection results for a pedelec redesign process 


\section{Conclusion and Outlook}

The last chapters presented different approaches on how the challenges for integrating sustainability targets into the design process (summarised in Fig. 3) can be addressed. For the specific case of modularisation, it was shown how the breaking down of sustainability design targets can be supported by qualitative causal diagrams (see Sect. 4.1). Nevertheless, qualitative visualisation of decision pathways can only be a first step towards decision support based on facts and data. What remains a challenge however, lies, in defining scenarios on how multiple sustainability design targets can be achieved by varying sub-targets for assemblies or subsystems. A lifecycle $\mathrm{CO}_{2}$ reduction target could be, for example, achieved by material substitution of a pedelec frame or the more costly development of an efficient motor. To properly take stock of these side effects and trade-offs, a parametric model becomes necessary, which serves to establish connections between the decision criteria of the three sustainability dimensions. These "dependency models" can be utilised for setting targets but also for minimizing the solution spectrum of possible design solutions.

In Sect. 4.2, a first prototype of a dependency model was presented with the simple example of a pedelec frame material selection regarding technical targets and a $\mathrm{CO}_{2}$ emission limits. The dependency model was represented in an ontological map and interpreted by a self-developed software tool. The model-prototype developed showed satisfying results, yet remains limited to a single component. In order to allow consideration of assemblies and complete products, more comprehensive models are necessary which comprise libraries of components from previous design projects that contain sustainability relevant information (e.g. material composition, GHG emissions, cost etc. (see Buchert et al. 2016). By following this approach, solution configurations can be identified which are compliant with a set of sustainability targets. In this context, model design must be simplified due to the fact that the effort for coupling different models in dispersed IT systems stands quite high.

In that pursuit of deeper understanding of the product's interrelation with sustainability impact, Sect. 4.3 presented a more process-oriented perspective on achieving sustainability design targets. By providing a selection scheme for SPD methods, the best suitable approach can be assigned to the tasks which are necessary for proving that sustainability design targets were achieved. In addition to the main findings of a corresponding literature analysis (see end of Sect. 2), a lack of methods considering all three sustainability dimensions was observed. While several methods focusing on environmental sustainability exist, approaches concerning social sustainability remain scarce. An integrated view of all three dimensions is indeed nearly non-existent. Furthermore, descriptions of several existing methods have only scratched the surface, while use cases for successful implementation are hard to come by. Nevertheless, the developed selection scheme and information 
platform presents the opportunity for combining heterogeneous approaches (such as qualitative guidelines and quantitative assessment methods) which allow for an overall more holistic perspective on the product.

\section{References}

Allenby, Braden R. 1991. Design for environment: A tool whose time has come. SSA Journal 12(9): 5-9.

Baumann, H., F. Boons, and A. Bragd. 2002. Mapping the green product development field: engineering, policy and business perspectives. Journal of Cleaner Production 10(5): 409-425. doi:10.1016/S0959-6526(02)00015-X.

Bretzke, Wolf-Rüdiger. 1980. Der Problembezug von Entscheidungsmodellen. 29: Mohr Siebeck.

Buchert, T., A. Kaluza, F.A. Halstenberg, K. Lindow, H. Hayka, and R. Stark. 2014. Enabling product development engineers to select and combine methods for sustainable design. Procedia CIRP 15: 413-418. doi:10.1016/j.procir.2014.06.025.

Buchert, T., A. Pförtner, J. Bonvoisin, K. Lindow, and R. Stark. 2016. Model-based sustainable product development. In Proceedings of the 14th International Design Conference, ed. Dorian Marjanovic, Mario Storga, and Neven Pavkovic, 145-154. Stanko Skec: Nenad Bojcetic.

Ciroth, Andreas, Jean-Pierre Theret, Mario Fliegner, Michael Srocka, Volker Bläsig, and Özlem Duyan. 2013. Integrating life cycle assessment tools and information with product life cycle management. In Proceedings of the 11th Global Conference on Sustainable Manufacturing, ed. Günther Seliger, 210-212. Universitätsverlag der TU Berlin.

Collado-Ruiz, Daniel, and Hesamedin Ostad-Ahmad-Ghorabi. 2013. Estimating environmental behavior without performing a life cycle assessment. Journal of Industrial Ecology 17(1): 31-42. doi:10.1111/j.1530-9290.2012.00510.x.

Duflou, Joost, and Wim Dewulf. 2005. Eco-impact anticipation by parametric screening of machine system components: An introduction to the EcoPaS methodology. In Product engineering: Eco-design, technologies and green energy, ed. Doru Talaba, and Thomas Roche, 17-30. Dordrecht: Springer Science + Business Media Inc.

Ernzer, M., and H. Birkhofer. 2002. Selecting methods for life cycle design based on the needs of a company. In Proceedings of the 7th International Design Conference, ed. Dorian Marjanovic, $145-154$.

Gleisberg, Jochen, Oliver Knapp, Stefan Pötzl, and Michael Becker. 2012. Modular productshow to leverage modular product kits for growth and globalization. http://www.rolandberger.fr/ publications/publications_monde/2012-04-10-Modular_Products.html.

Kara, Sami, Suphunnika Ibbotson, and Berman Kayis. 2014. Sustainable product development in practice: an international survey. International Journal of Manufacturing Technology Management 25(6): 848-872. doi:10.1108/JMTM-09-2012-0082.

Neugebauer, Sabrina, Julia Martinez-Blanco, René Scheumann, and Matthias Finkbeiner. 2015. Enhancing the practical implementation of life cycle sustainability assessment-proposal of a Tiered approach. Journal of Cleaner Production 102: 165-176. doi:10.1016/j.jclepro.2015. 04.053.

Neugebauer, Sabrina, Ya-Ju Chang, Markus Maliszewski, Kai Lindow, Rainer Stark, and Matthias Finkbeiner. 2013. Life cycle sustainability assessment \& sustainable product development: A case study on pedal electric cycles (Pedelec). In Proceedings of the 14th Global Conference on Sustainable Manufacturing, ed. Günther Seliger, 549-554. Universitätsverlag der TU Berlin.

Ny, Henrik, Sophie Hallstedt, Karl-Henrik Robèrt, and Göran Broman. 2008. Introducing templates for sustainable product development. Journal of Industrial Ecology 12(4): 600-623. doi:10.1111/j.1530-9290.2008.00061.x. 
Pförtner, A., T. Buchert, K. Lindow, R. Stark, H. Hayka. 2016. Information management platform for the application of sustainable product development methods. Procedia CIRP 48: 437-442. doi:10.1016/j.procir.2016.04.091.

Shuaib, Mohannad, Daniel Seevers, Xiangxue Zhang, Fazleena Badurdeen, Keith E. Rouch, and I. S. Jawahir. 2014. Product sustainability index (ProdSI). Journal of Industrial Ecology 18(4): 491-507. doi:10.1111/jiec.12179.

Stark, Rainer, and Anne Pförtner. 2015. Integrating ontology into PLM-tools to improve sustainable product development. CIRP Annals-Manufacturing Technology 64(1): 157-160. doi:10.1016/j.cirp.2015.04.018.

Steffen, Will, Katherine Richardson, Johan Rockström, Sarah E. Cornell, Ingo Fetzer, Elena M. Bennett, Reinette Biggs, Stephen R. Carpenter, Wim de Vries, and Cynthia A. de Wit. 2015. Planetary boundaries: Guiding human development on a changing planet. Science 347(6223): 1259855. doi:10.1126/science.1259855.

Telenko, Cassandra, Julia M. O'Rourke, Carolyn C. Seepersad, and Michael E. Webber. 2016. A compilation of design for environment guidelines. Journal of Mechanical Design 138(3): 31102. doi:10.1115/1.4032095.

Weber, Christian, Horst Werner, and Till Deubel. 2003. A different view on product data management/product life-cycle management and its future potentials. Journal of Engineering Design 14(4): 447-464. doi:10.1080/09544820310001606876.

Open Access This chapter is licensed under the terms of the Creative Commons Attribution 4.0 International License (http://creativecommons.org/licenses/by/4.0/), which permits use, sharing, adaptation, distribution and reproduction in any medium or format, as long as you give appropriate credit to the original author(s) and the source, provide a link to the Creative Commons license and indicate if changes were made.

The images or other third party material in this chapter are included in the book's Creative Commons license, unless indicated otherwise in a credit line to the material. If material is not included in the book's Creative Commons license and your intended use is not permitted by statutory regulation or exceeds the permitted use, you will need to obtain permission directly from the copyright holder.

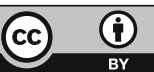

